\begin{tabular}{|c|c|c|}
\hline Received 13.07.2021 & \multirow{3}{*}{ Research Article } & \multirow{3}{*}{$\begin{array}{c}\text { JOTS } \\
5 / 2 \\
2021: 380-392\end{array}$} \\
\hline Accepted 21.07.2021 & & \\
\hline Published 24.07.2021 & & \\
\hline
\end{tabular}

\title{
Göz Hastalıkları ve Tedavileri Üzerine Eski Uygurca Sūtra'lardan Parçalar
}

\author{
Some Old Uygur Fragments about Eye Diseases und their Treatments
}

\author{
Osman Fikri SERTKAYA** \\ İstanbul/Turkey \\ E-mail: sertkayaof46@gmail.com
}

Some Buddhist sūtras have sections on medicine. Two of them are related to eye diseases and their treatments. Each side of the fragments has 9 lines. The Fragments belong to Padmacintāmani-dhāranisūtra and Nilakantakasūtra. In the article, they are firstly transcribed and translated. Then, the names of the drugs in the text were examined and compared with other works.

Key Words: Old Uygur fragments, Mainz 244, Mainz 212, Padmacintāmani-dhāraṇi-sūtra, Nīlakantakasūtra.

Bu bildirimi 17-20 Eylül 1996'da İstanbul'da toplanan IV. Türk Tip Tarihi Kongresi'nde Göz Hastalkları ve Tedavileri Üzerine Eski Uygurca Sütralardan Parçalar başlı̆̆ ile sunmuşum. Ancak Ağustos 1996'da profesörlük kadrosuna atanmam esnasında metnin yayınını ihmal ettim. Sonra da bu konuya geri dönmedim. 2020 yılında Peter Zieme benden bu bildirimin kopyasını istedi. Eski bilgisayarımdan bularak kendisine gönderdim. Uygurca parçaları gözden geçirerek yayımlanması için JOTS’a gönderdim. Böylece gecikmiş bir yayını gerçekleştirmiş oluyorum.

** ORCID ID: 0000-0003-4637-7308. 


\section{1)}

\section{Giriş}

1989'da Uluslararası Osmanlı Öncesi Türk Kültürü Sempozyumu'nda (International Symposium on Pre-Ottoman Turkish Culture, Ankara, 4-7.9.1989) sunduğum Uygur Tıp Metinlerine Toplu Bir Bakış adlı bildirimde bazı Budist sūtra'lardaki tıp unsurları üzerinde durmuştum. Göz Hastalıkları ile Tedavileri Üzerine Eski Uygurca Sūtra'lardan Parçalar adlı bu bildirimde ise Padmacintāmanidhārani-sūtra ile Nïlakanta[ka]sūtra'daki göz hastalıkları ile ilgili bölümler üzerinde durmak istiyorum.

\section{Padmacintāmani-dhāraṇi-sūtra}

Padmacintāmani-dhāraṇi-sūtra adı ile bilinen metnin Eski Uygur Türkçesine çevirisinin içerisinde çintamani darnı nom üzeki köz otın ka[tmak] başlıklı bölüm göz hastalıkları ve tedavilerinden bahsetmektedir. Sūtra'nın British Museum, Or. 8212 (158)'de kayitlı olan Sogdça tercümesinin bir bölümü, Taishō, 1082, 20, 199b/13'te kayıtlı olan Çincesi ile karşılaştırılarak, 1926 yılında F. W. K. Müller ve 1963 yılında da D. N. Mackenzie tarafından yayımlandı. Doğu ve Batı Almanya birleştikten sonra Uygur yazmalar koleksiyonunun bulunduğu Doğu Berlin Bilimler Akademisi (Akademie der Wissenschaften der DDR)'nin adı BerlinBrandenburgische Akademie der Wissenschaften adını aldı. Mainz'de bulunan yazma parçaları da Berlin'e nakledilerek Akademinin Turfanforschung (Turfan Araştırmaları) bölümünde muhafaza ediliyor.

Padmacintāmani-dhāraṇi-sūtra, Taishō, 20, 1082, 199 a18'de başlayı1p 199 b2'de sona ermektedir. Her sahifesinde $9+9=18$ satırlık metin ihtiva eden Uygurca metnin Berlin'deki parçaları şunlardır:

1. Taishō, 20, 197 c5'te başlayan metin parçası: 1.-18. satırlar. Ancak U 3571'de 18 satırlık sahifenin satır sonlarından 5'er satırın parçaları kalmıştır.

2. Taishō, 20, 197 c21-198a1 arasındaki metin parçası U 2307 (T I D 93) + Mainz 218'de olmak üzere 19.-36. satırlar. Ancak U 2307'de satır başlarından 5'er satır. Mainz 218b'de ise sağdan ve soldan eksik 9'ar satır kalmıştır.

3. Taishō, 20, 198 c6'da başlayan metin parçası: U 2305 (T I D 93)'de 37.-54. satırlar. Sahifenin orta bölümünden üstten 6 , alttan 6 satırın bölümleri kalmıştır.

4. Taishō, 20, 198 c19'da başlayan metin parçası. Uygurca metnin dördüncü bölümünün 55.-

72. satırları olarak U 2209'da 9'ar satır. 


\section{$\mathrm{J}(\mathrm{O})$}

5. Taishō, 20, 199a18'de bulunan metin parçası Uygurca metnin dördüncü bölümünün üçüncü (?) yaprağındaki 75.-90. satırlar olarak Mainz 244 (T I 551)'de 9'ar satır. Sūtra'nın tıp ile ilgili parçası bu yaprakta bulunmaktadır.

Skr. dhāraṇi metni ise Otani, Ryukoku, 1370'de Uygur harfli 19 satırda geçmektedir. Sūtra'nın tıp ile ilgili parçası Mainz 244’te kayıtlı olan yaprakta bulunmaktadır.

Prof. Dr. Peter Zieme'den aldığım 28.8.1996 tarihli mektuba göre yazma parçalarının bazı sahifeleri de Rusya, St. Petersburg'da bulunmaktadır. Zieme, metinlerin tamamını L. Yu. Tuguşeva ve Gy. Kara ile beraber yayıma hazırlanmakta olduğunu da yazmıştır.

Metinde geçen Aryavalokiteśvara Boddhisattva hakkında da kısaca bilgi vermek isterim. Skr. ārya avalokiteśvara boddhisattva > Uyg. aryavalokiteşvar bodisatav Mahāyāna burkancllı̆̆ının önde gelen tiplerinden birisidir. Canlı varlıklara sonsuz bir acıma hissi duyan, insanların çeşitli dileklerini yerine getiren, sıkıntıya düştükleri zaman Hızır gibi yetişen ve onlara Nirvāna yolunu gösteren dişi bir ilâhtır. Amitābha Buddha'nın batı cennetini idare etmektedir.

\section{Mainz 244 r (TI 551)}

(1) çintamani darnı nom üzeki köz otın ka[tmak] ... bişinç .. ol (2) ödün ıdok

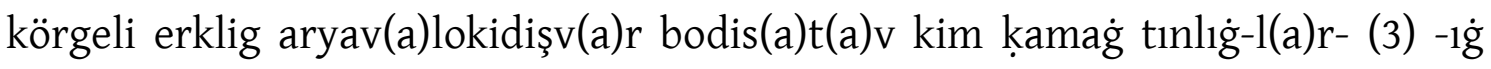
irinçkeyü tsuyurḳayu y(a)rlıkap köz otın ḳatmak törü[sin? ḳa]maǵ kişi kör (4) [s]er sevgülük tapla-ġuluk ögirgülük sevingülük nomlayu [y(a)rlık]adı .. (5) [ot ]ları bo erür .. kakoti ... kişirakakoti .. yipün len[hua kök] .. (6) [lenhu]a taloy köpüki .. ḳuzġun otı .. balık tü[......................] (7) [kürkü]m .. tavġaç kürkümi .. p(i)tpidi .. mırça .. bışıg s[ıngır ............] (8) [ .... ] ḳılıp yinçge soḳup alap ertmişte kin .. a[ ] (9) [ ... s]aḳar .. kapir .. yar[ıma]r sıtır urup yinçge kinl[emişte? 1dok körgeli]

(1) çintamani darnı nom'a göre göz ilacının terkibi. beşinci (bölüm): (2) O zaman mukaddes, her şeyi gören, asil, Avalokiteśvara Boddhisattva bütün canlılara (3) acıyarak, bağışlayarak, merhamet ederek göz ilacının terkibi usulünü herkes görse diye (4) severek ${ }_{2}$ sevinerek $_{2}$ açıkladı: (5) ilaçları budur: kakoti, kişirakakoti, yipün lenhua, kök (6) lenhua, taloy köpüki, kuzgun otı, balık tü[... (7) Çin safranı, pitpidi, mırça, bışı̆̆ sıngır ... (8) [aynı oranlarda], iyice dövüp, 


\section{ग(৫)}

karıştırdıktan sonra [bir onsu geçmeyen ilâca] (9) yarımşar ölçü misk ve kafuru katıp ince [ezildiğinde mukaddes, her şeyi gören]

\section{Mainz 244 v (TI 551)}

(10) [erklig] aryav(a)lokidişv(a)r bo[di]s(a)t(a)v körki öyinte k[ ................. ] (11) [ ...... ] birisin min sekizer ḳata sözlep .. alḳ[o ḳamaǵ tınlığlar üçün] (12) [edgü?] ögli y(a)rlıḳançuçı köyül turǵurup bo otug ıdo[k körgeli erklig ary] (13) [av(a)l]okidişv(a)r bo[di]s(a)t(a)v körki-niy adakıınta [.............] (14) [kı1zıl bakıır çöki öze köz buluyınta tamazs[ar öyedge]y (15) [ka]mag்-nıy ağrıg erser inçe k.(a)ltı <közte> kön örtmek [......]k (16) böri tüşmek .. yaş aḳmak .. kııarmak k(a)raġu bolmak .. köz aǵrı[mak]da ulatı .. (17) kün küntemek birer kata bo [otug்] közde ursar barça öyedür .. iki kün (18) ursar tolp et’özdeki ig aġrı́g-ḳa em [bolur] .. üç kün [ursar

(10) asil, Avalokiteśvara Boddhisattva güzelliği önünde ... (11) ... birini bin sekizer defa söyleyerek, bütün [canlılar için] (12) [iyi] kalple ve merhametle düşünerek bu ilacı mukaddes, her şeyi gören, (13) asil, Avalokiteśvara Boddhisattva güzelliği huzurunda [sundu] (14) kızıl bakır çöki ile göz kenarına damlat[sa, iyileştirecektir]. (15) hepsinin hastalığı ise, şöyle ki gözün bir deri ile örtülmesi, ... (16) çapaklanmak, yaş akmak, kızarmak, katarakt olmak, göz ağrımak ve (17) göze perde inmek birer defa bu göze vursa, hepsini iyileştirir. iki gün (18) vursa, bütün vücuttaki hastalıklara ilaçtır. üç gün [vursa ...

\section{Nīlakanta[ka]sūtra}

Hintçeden Çinceye VII. yüzyılda Hintli rahip Bhagavaddharma tarafından çevrilmiştir. Taisho, 20, 1060, 110 a26'da başlayıp 110 b6'da sona ermektedir. Eserin başlı̆̆ 千手千眼觀世音菩薩廣大圓滿無礙大悲心陀羅尼經 Qianshou qianyan Guanshiyin pusu guangda yuanman wuai dabeixin tuoluoni jing "The Great Complete Dhārān-Sūtra of the 1000-handed and 1000-eyed Boddhisattva Guanshiyin [Avalokiteśvara]" şeklindedir. Sūtra'nın Uygur Türkçesi çevirisinin başlığı şöyledir: ming közlüg ming iliglig ıduk yarlıkançuçı köngül atl(ı)g darnı nom.

Zieme'ye göre ig 'hastalık' olmalı idi. Yani müstensih ig 'hastalık' kelimesini \{+(X)g\} akuzatif eki zannetmiş ve yerine $\{+$ nIy $\}$ genitif ekini yazmış olmalı. 


\section{1(0)}

Uygurca metnin göz hastalıkları reçetelerini ihtiva eden parçası Mainz 212'de [= T I D 667c / T M 261c] kayıtlı olup her yüzde dokuzar satır olmak üzere 18 satırlık metnin ihtiva etmektedir.

Sūtra, M. D. Reis-Habito tarafından Almancaya çevrilerek yayımlanmıştır (1993). Uygurca metnin bir parçası K. Röhrborn tarafından yayımlanmıştır (1976). Bu yazma ile ilgili olarak Ş. Tekin (1965) ile P. Zieme'nin (1976) de araștırmaları bulunmaktadır.

\section{Mainz 212 r [= T I D 667c / T M 261c]}

(1) [-g்u ol uvşaḳıg bo ıdok darnı nom üze yet[i ḳata arvap em] (2) [-gen]miş orunta ursar ötrü öyedür .. kim ḳ[ayu ayığ ögli ..] (3) yağı yala yayḳu kemişip emgekke tegürgeli kı1[ın]sar .. ötr[ü arı́g] (4) t[opra]k alıp .. azu min .. azu lav alıp ol kişi et’özi[n] (5) ḳılıp min közlüg bodis(a)t(a)v körki üskinte ḳurç biç[ek?] (6) alıp .. bo ıdok darnı nom öze yüz sekiz ḳata arvap-p (7) açınmış-ta ol kişi et’özin birer kesser .. munçulayu ḳılu yüz sek[iz] (8) pin ḳılıp anıy atın atap ootka köyürser [küy]e tükedmiş_-te] (9) ötr[ü o]l ayıg ögli yaǵı bo kişi üze a[mrak ögrün]çülü[g ]

(1) o küçük parçayı bu mukaddes darnı nom iyi [düşünceli (2) ulaştığı yerde yerleştirse (koysa) tedavi eder. Kötü düşünceli (3) düşman iftira atarak zahmet verse, o zaman (4) toprak alarak ve un ve lav alarak o kişinin vücudunda (5) edip bin gözlü boddhisattva güzelliği huzurunda çelik bıçak (6) alarak bu mukaddes darnı nomu yüz sekiz defa okuyup (7) ...... o kişi vücudunu birer kesse, bunun gibi ederek yüz sekiz (8) parça edip onun adını söyleyerek ateşte yaksa, ... tükettiği (9) dolayısıyla o fena düşünceli düşman bu kişi ile ...

\section{Mainz 212 v [= T I D 667c / T M 261c]}

[baştınḳı bir] altmış (10) bolur [bu] azunta ölü ölginçe bo kiş[i sevgey tapla] (11) -ġay ayaǵay aġırlaǵay .. kim-ler birök köz a[ġrı̇g] bolup kün b[ol] (12) -sar .. közi emzik bolup böri tüşser .. ötrü .. ariri .. viriri .. imi[ti] (13) bo üç otug alıp yinçge sokup alap kinlep .. kinlemi[ş] (14) ödte arıg közedip kunçuy-larig .. 1tı̇ .. tonuzu[g்] (15) yakıı kelürmedin olar-ḳa körkitmedin aġızınta burhan (16) atın atayu bo ıdok darnıg sözleyü .. mir .. azu [ur]ı o[g்lan-lig்] (17) kisi süti birle katıp yoġurup yas[s]1 k1lıp közde [ ... ] (18) [min] közlüg bodis(a)t(a)v körki üskinte bo ıdok darnı no[m-uğ oḳıu? ] 
(10) olur bu dünyada. Bu kişiye uyacak, itaat ede- (11) -cek, saygı-hürmet duyacak. kim göz hastalığına yakalanıp ... (12) -se, gözünde arpacık çıkıp (gözü) çapaklansa, bu yüzden ariri, vriri, imiti (13) bu üç ilacı alıp iyice dövüp karıştırıp ezdiği (14) vakitte temiz tutup hanımların iti ve domuzu (= ev hayvanları) (15) yakın gelmeden, onlara göstermeden ağzında Buddha'ların (16) adını anarak bu mukaddes darnıyı söyleyerek bal ve erkek çocuklu (17) kadın sütü ile karıştırıp yoğurup yassı edip gözde ... (18) bin gözlü Boddhisattva .... huzurunda bu mukaddes darniyı okuyarak.

18 satırlık bu metin sūtra'nın III. bölümünden olup Reis-Habito tarafından tarafından Almancaya şöyle çevrilmiştir (1993: 193-194):

"Wenn jemand von bösartigen Schlangen und Tausendfüßlern gebissen worden ist, nehme man trockene Ingwerwurzel und spreche das Mantra einundzwanzigmal. Man trage sie auf die Schwellungen auf, und sie sind sofort verschwunden und geheilt. Wenn jemand aus Neid und Übelwollen eine Perversität ausheckt, nehme man reine Erde, Mehl, oder Wachs, bilde daraus seine Gestalt und spreche des Mantra vor der Statue des Tausendäugigen einhundertundacht mal über ein Eisenmesser. Bei jedem Mantra mache man einen Schnitt und rufe einmal seinen Namen. Dann verbrenne man die einhundertundacht Stücke wollständig. Dann wird (der Neider) sich frauen, sein ganzes Leben lang würdig und anderen gegenüber liebe- und respektvoll sein. Wenn es an Augenkrankheiten Leidende gibt, wie solche mit blinder Pupille oder verdunkelten Auge, oder solche mit bedecktem oder rotem Augenweißen und glanzloser Membran, nehme man von den drei Arten von Hārìtakī, Amalā und Vibhïtaka jeweils eine Frucht und zerreibe sie in einem Mörser zu feinem Pulver. Wenn man sie zu Pulver macht, muss man vor allem auf die Reinheit achten und nicht in die Nähe von Freuen, die gerade geboren haben, Hunden und Schweinen kommen lassen. Mit dem Munde rufe man Buddha an und verschließe mit einem Gemischt von weißem Honig und Muttermilch das Auge. Die Milch, die man dem Menschen aufträgt, muss die Milch der Mutter eines Jungen sein. Die Milch der Mutter eines Mädchens hat keine Wirkung. Wenn die Medizin fertig ist, rezitiere man das Mantra eintausendundacht mal vor der Statue des Tausendäugigen".

\section{Metinlerde Zikredilen Hastalıklar}

1. közte kön örtmek = gözün perde ile örtülmesi

2. $[\ldots . . ..] \mathrm{k}=$ ?

3. böri tüşmek = gözün çapaklanması

4. yaş aḳmak = gözden yaş akması

5. kııarmak = gözün kızarması

6. k.(a)ragiu bolmak = katarakt olmak 
7. köz ag̉rımak = gözün ağrıması

8. kün küntemek = gözün puslanmas1

9. közi emzik bolup böri tüşmek = gözünde arpacık çıkıp çapaklanmak

Arat tarafından yayımlanan Zur Heilkunde der Uiguren adlı eserin (1930) ilk cildinde bu göz hastalıklarının bazılarının tedavi usulleri reçeteleriyle birlikte zikredilmektedir. Metinde üçüncü sırada geçen 'gözün çapaklanması' ile ilgili olarak verilen reçete R. R. Arat tarafından 'gözün kurtlanması' şeklinde verilmiştir.

\section{Börilig Köz 'Çapaklı / Kurtlu Göz'}

yana kişi ötin alıp börilig közke sürtser açılur (Rachmati, 1930: 60-61) "yine insan ödünü alıp kurtlu göze sürtse, (göz) açllır."

4. sırada geçen 'gözden yaş akması' ile ilgili olarak gözden çok yaş akması, gözden soğuk yaş akması ve gözden sıcak yaş akması hakkındaki reçeteler ise şöyledir:

\section{5. yaş akmak 'gözden yaş akması'}

köz ag̉rig̉ em-i köz küçsirep yaş aksar ballk ödin közke alın-[ka] sürtser edgü bolur (Rachmati, 1930: 155-156) "Göz hastalığı ilâcı: Göz(ün görmesi) zayıflar ve gözden yaş gelirse, balık ödini göze ve alına sürtse, iyi olur."

\section{6. yaş akmak 'gözden çok yaş akması'}

köz yaruk-suz bolup üküş telim yaş akssar köz öze <kum-a yag்-in> sürtser y(i)me edgü bolur (Rachmati, 1930: 65-66) "Göz puslanıp çok fazla yaş aksa, göz üzerine (kendir yağı) sürtse, yine iyi olur."

\section{7. soğuk yaş akmak 'gözden soğuk yaş akması'}

köz emi başlatı: köz yaruksuz bolup közte telim savuk yaş akssar, ut ödin közke sürtser köz yaruk bolur (Rachmati, 1930: 85-86) "Göz ilâcı başladı: Göz puslanıp, gözden çokça soğuk yaş aksa, sığır ödünü göze sürtse, göz berrak olur.” 


\section{ग(৫)}

\section{8. sıcak yaş akmak (gözden sıcak yaş akması)}

yana em: közte isig yaş akssar yig şeker sarıg muna çurnı kıllip ingek yaġı birle katıp burunka kodsar edgü bolur (Rachmati, 1930: 87-88) "Yine ilâç: Gözden sıcak yaş aksa kamış şekeri ile sarı mungayı toz edip, inek yağı ile karıştırıp, buruna koysa, iyi olur."

Metinde geçmemekle birlikte Heilkunde'de geçen başka göz hastalıkları da vardır. İlgileri dolayısıyla onları da burada zikrediyorum:

9.

köz lan bolup körmeser çüvit-ni suv-ka simlep kinlep alnn-ka sürtser edgü bolur [.] (Rachmati, 1930: 156-158) “Göz lan olup görmezse, çivit’i suya koyup eritip alına sürtse, iyi olur.

\section{0.}

köz ag̉rig em kişi öti tonuz öti eçkü öti tavış̧kan öti bu törtegü-te kayu-sı bolsar kara kar-a kaç ığaç kasılk-ın kasık-ın ot-ka kara küyürüp kkül-in alı suv-ḳa yog்urup közke yakgiu ol, bat edgü bolur [.] (Rachmati, 1930: 24-28) "Göz hastalı̆̆1 ilâc1: insan ödü, domuz ödü, keçi ödü tavşan ödü, bu dördünden hangisi olsa kaç ağacının göbeğini atește yakıp, külünü alıp, su ile yoğurulup, göze sür. (göz) hemen iyi olur."

\section{1}

kim-niy közin aġızın yiil tartıp kıyık kılmış erser kunduz kayır-ı suv-ta kinlep türtsün küzüngü-te körzün (Rachmati, 1930: 124-126) “Kimin gözünü, ağzını yel vurup çarpmış ise Kunduz taşağını suda ezip (çarpılmış) yere sürsün. aynada görsün."

\section{2}

kayu kişi keçe edgü körmeser kar-a eçkü-nüng ögsüz baġır-ın-ḳa içige kara keçinin ögsüz cigerinin içine pidpidi-ni saçıp ot-ka kömüp köpik-in alp közge sürtgül, kiçe edgü körür. (Rachmati, 1930:33-36) "Hangi kişi gece iyi görmüyorsa, karabiberi saçarak ateşe eteșe gömüp, köpüğünü alarak göze sürt, gece iyi görür.” 


\section{ग(৫)}

\section{3}

kekelik ötin şeker birle tüz ülüş ḳllip közke sürtser, körmeser yme körür, edgü bolur. (Rachmati, 1930: 50-51) "Keklik ödünü aynı miktarda şeker ile karıştırıp göze sürtse, görmüyorsa da görür, (göz) iyi olur."

\section{Metinde Zikredilen İlâçlar}

1. kakoti < Skr. kākoli: kakkola 'a species of plant (bearing a berry, the inner part of which is waxy and aromatic)' (Monier Williams, 1899: 241c). Skr. kakoti kelimesi Dîvânü Lugati't-Türk'te kek otı şeklinde Türkçeleştirilmiştir.

2. kişirakakoti < Skr. kșīrakākoli 'Name einer Wurzel aus dem Himalaya, die einen Saft absondert, der als eines der acht Hauptmedikamente dient'. Kṣīrakākoli(ka).

3. yipün len[hua] = kırmızı nilüfer.

4. kök lenhu]a = mavi nilüfer.

5. taloy köpüki: Lületaşı, Hidratlı tabii Magnezyum silikat, Magnezit ‘Meerschaum' bk. Rachmati, 1930: 103.

6. kuzgiun ot1 = kuzgun otu 'Rabenkraut'.

7. balık tü[...] = ?

8. [kürkü] $] \mathrm{m}=$ safran

9. tavġaç kürkümi $=$ Çin safranı

10. p(i)tpidi =<skr. 'Piper longum' = 'karabiber': ka[yu] kişi kiçe edgü körmeser kar-a eçkü-nüg ögsüz baġır-ın-ka içige pidpidi-ni saçıp ot-ka kömüp köpik-in alıp közke sürțül, kiçe edgü körür (Rachmati, 1930: 33-36) "Hangi kişi gece iyi görmezse kara keçinin ögsüz ciğerinin içine karabiberi saçıp ateşe gömüp köpüğünü alıp göze sürt. Gece iyi görür."

11. mırça < skr. marica 'bir biber cinsi, karabiber, Piper nigrum'. Türkçedeki mırç murç için bk. Clauson, 1972: 771b-772a.

12. bışığ s[ığır]: Bk. pişmiş Zencefre 'getrockneter Ingwer' (Bailey, 1953: 5156). 


\section{ग(৫)}

13. sakar = Misk: kekelik ötin sakar [şeker?] birle tüz ülüğ kıllp közke sürtser körmeser yme körür, edgü bolur [.] (Rachmati, 1930: 50-51). "Keklik ödünü aynı miktarda misk ile karıştırıp göze sürtse, görmeyen göz görür ve iyi olur”; yana em: közte isig yaş akssar yig saḳar sarıg munǵa çurnı ḳllip ingek yaġı birle katıp burunka kodsar edgü bolur (Rachmati, 1930: 87-88) "yine ilâç: gözden sıcak yaş aksa iyi misk (ile) sarı munga(yı) (şeker?) toz edip, inek yağı ile karıştırıp buruna koysa iyi olur."

14. kapir < skr. karpūra. Kâfuru. /r/ düşmesi için krş. kerek < kergek

15. ariri< skr. haritaki 'Halîle', Terminalia Chebula (Roxb.). Bk. Röhrborn, 1981: 195a-b; Bedevian, 1936: 3368; Baytop 1984: 242. Krş. Rachmati, 1932: 1/15, 77; 2/84; 3/67, 176, 221; 4/13. a.-n1 1/83; a. uruġ1 3/124; sarıg a. 1/8, 22.

16. viriri < skr. vibhītakī $\sim$ vibhītaka = Çince pi li lo (Giles, 1912: 90506888 6814 le 7316 lo veya lei), bk. Laufer, 1919: 378. 'Balilec' 'Terminalia Bellerica (Roxb.)'. Bk. Bedevian, 1936: 3366.

17. imiti < skr. āmalaka 'Amlac', 'Emblica Officinalis (Roxb., Gaertnr.)', yeni terim 'Phyllanthus ᄀsemblica (Linne)'. Bk. Bedevian, 1936: 2654. (Krş. Rachmati, 1932: 1/22, 4/14 ve krş. Mainz 684 (Br.) z (v) : ām[a]1[a]k[a]).

\section{Kaynakça}

Bailey, H. W. (1953). Medicinal plant names in Uigur Turkish. In 60. Doğum Yll Münasebetiyle Fuad Köprülü Armağanı, Melanges Fuad Köprülü (pp. 51-56). Osman Yalçın Matbaasi.

Baytop, T. (1984). Türkiye'de Bitkiler ile Tedavi (Geçmişte ve Bugün). İstanbul Üniversitesi Yayınları.

Bedevian, A. K. (1936). Illustrated polyglottic dictionary of plant names in Latin, Arabic, Armenian, English, French, German, Italian, and Turkish languages including economic, medicinal, poisonous and ornamental plants, and common weeds. Argus \& Papazian Presses.

Clauson, S. G. (1972). An Etymological Dictionary of Pre-Thirteenth-Century Turkish. Oxford University Press.

Giles, A. H. (1912). A Chinese-English Dictionary I-II. Kelly and Walsh. (Revised \& Enlarged) 


\section{1)}

Laufer, B. (1919). Sino-Iranica; Chinese contributions to the history of civilization in ancient Iran, with special reference to the history of cultivated plants and products. Field Museum of Natural History.

Mackenzie, D. N. (1976). The Buddhist Sogdian Texts of the British Library. Bibliothèque Pahlavi.

Monier-Williams, S. M. (1899). A Sanskrit-English Dictionary, Etymologically and Philologically Arranged with Special Reference to Cognate Indo-European Languages. Motilal Banarsidass Publishing Hous.

Müller, F. W. K. (1926). II. Reste einer sogdischen Übersetzung des Padmacintāmani-dhārani-sūtra. Sitzungsberichte der Preussischen Akademie der Wissenschaften. Phil.-Hist. Klasse 1926, 2-8.

Rachmati, R. (1930). Zur Heilkunde der Uiguren [I]. Sitzungsberichte der Preussischen Akademie der Wissenschaften. Phil.-hist. Kl. 1930, 452-473.

Rachmati, R. (1932). Zur Heilkunde der Uiguren II. Sitzungsberichte der Preussischen Akademie der Wissenschaften. Phil.-hist. Kl. 1932, 401-448.

Reis-Habito, M. D. (1993). Die Dhāraṇi des Großen Erbarmens des Boddhisatva Avalokiteśvara mit tausend Händen und Augen. Übersetzung und Untersuchung ihrer textlichen Grundlage sowie Erforschung ihres Kultes in China. Routledge.

Röhrborn, K. (1976). Fragmente der uigurischen Version des "Dhāraṇī-Sūtras" der großen Barmherzigkeit. Die Zeitschrift der Deutschen Morgenländischen Gesellschaft. 126, 87-100.

Röhrborn, K. (1981). Uigurisches Wörterbuch. Sprachmaterial der vorislamischen türkischen Texte aus Zentralasien III. Franz Steiner Verlag.

Sertkaya, O. F. (1989). Türkçe Tıp Metinlerinde Lületaşı. In Eskişehir II. Uluslararası Lületaşı ‘Beyaz Altın’ Festivali, “Beyaz Altın Semineri”, 23 Eylül 1989 (pp. 17-19).

Tekin, Ş. (1965). Uygur Bilgini Singḳu Seli Tutung'un Bilinmeyen Yeni Bir Çevirisi Üzerine. Türk Dili Araştırmaları Yıllığı Belleten 1965, 29-33.

Zieme, P. (1976). Sïngqu Säli Tutung-Übersetzer buddhistischer Schriften ins Uigurische. In Heissig, W. (Eds.), Tractata altaica: Denis Sinor, sexagenario optime de rebus altaicis merito dedicata (pp. 767-775). Harrassowitz Verlag. 


\section{I(O)}

\section{Resimler $^{2}$}

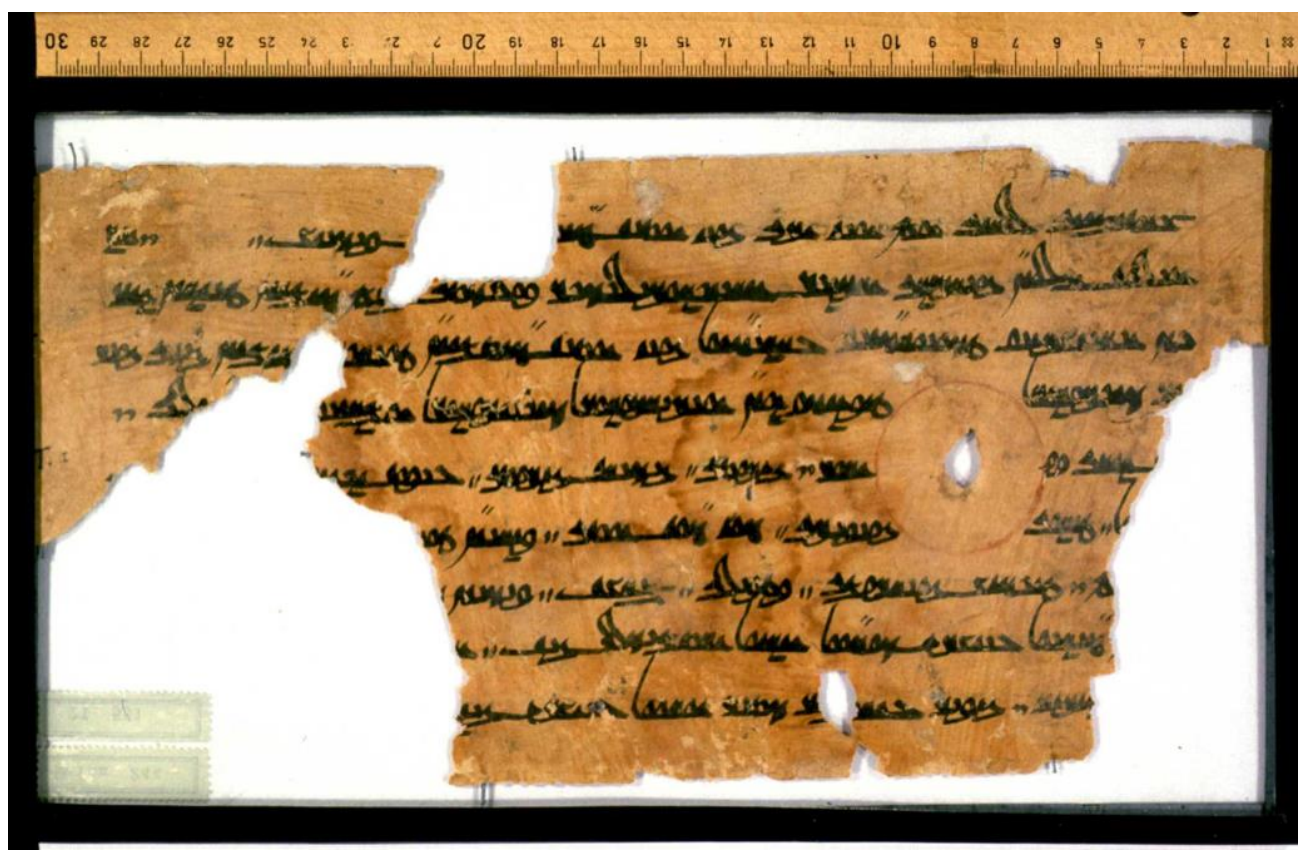

Resim I

Mainz 244 r (T I 551)

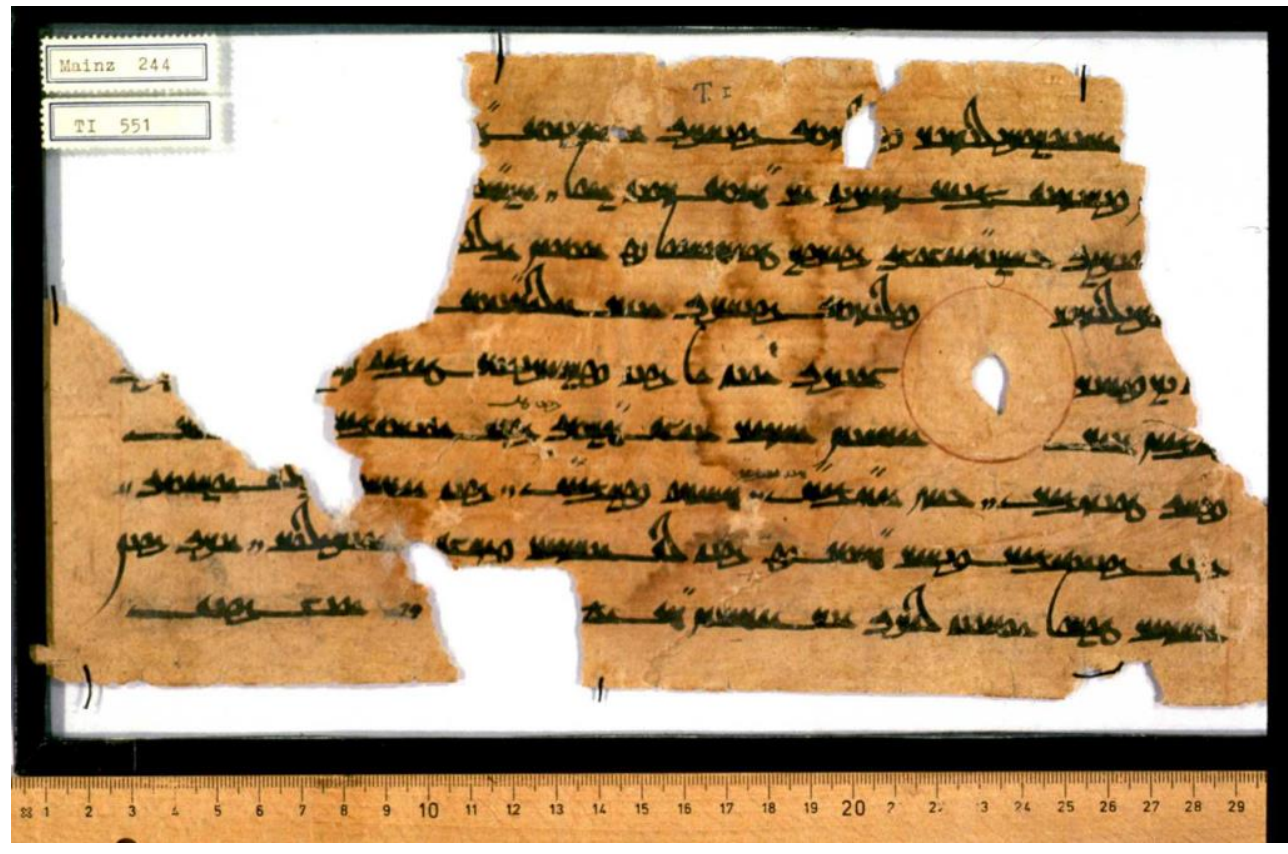

Resim II

Mainz 244 v (T I 551)

\footnotetext{
2 Resimler, Berliner Turfan-Sammlung'un internet sitesinden (www.turfan.bbaw.de) alınmıştır.
} 


\section{$\mathrm{J}(\mathrm{O})$}

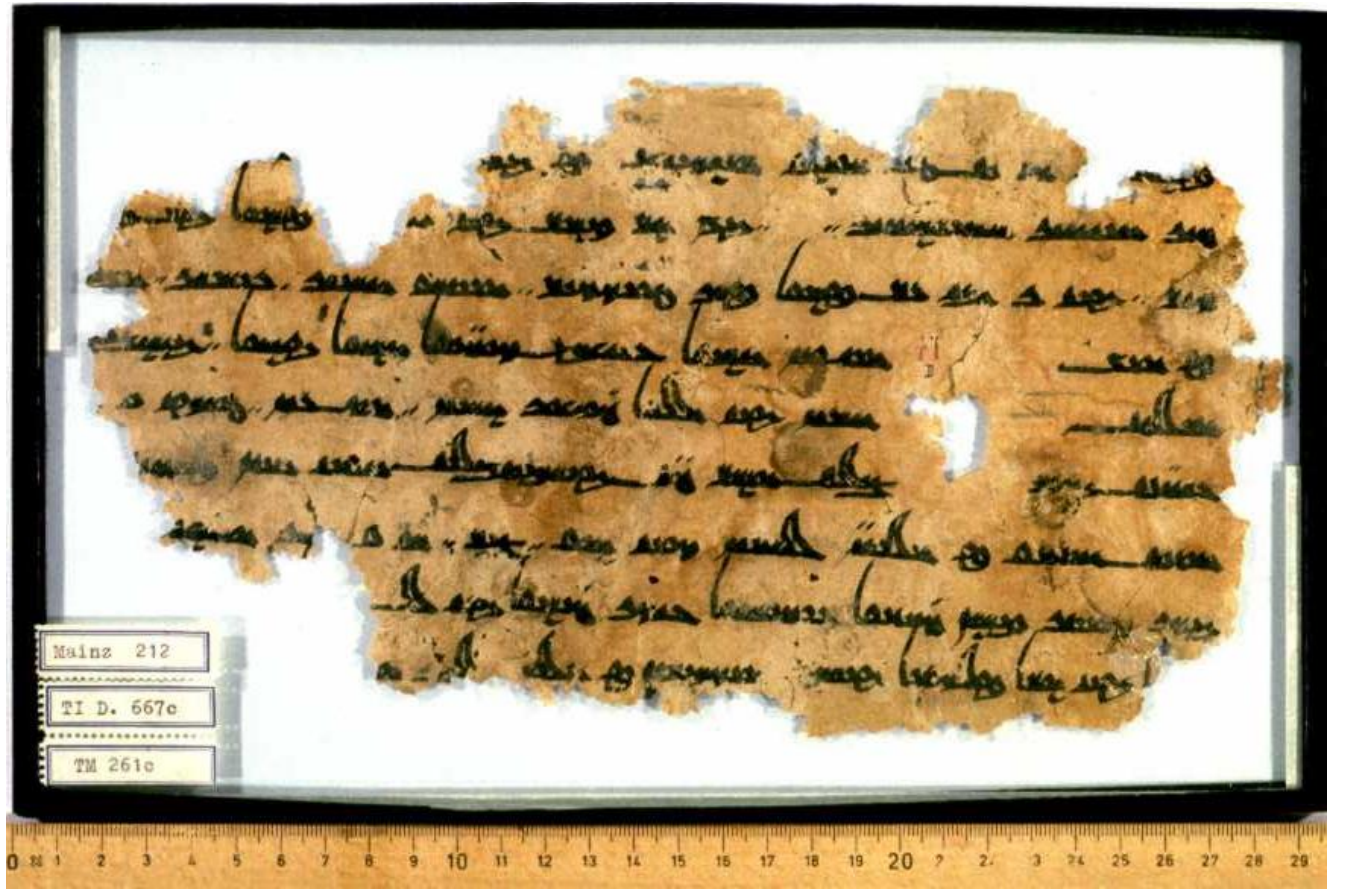

Resim III

Mainz 212 r (T I D 667c / T M 261c)

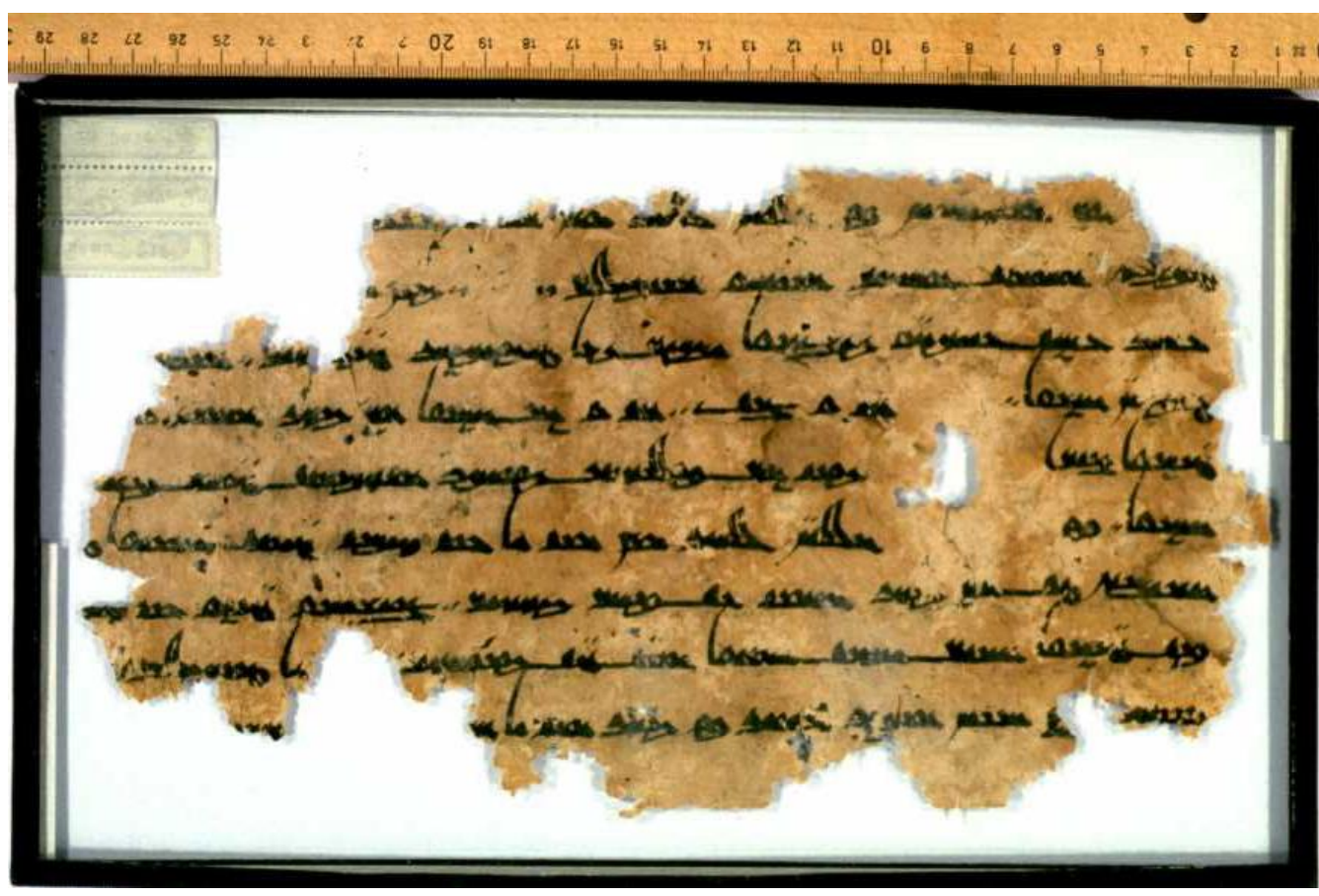

Resim IV

Mainz 212 v (T I D 667c / T M 261c) 